\title{
Deaf Studies as a transformed and transformational field: inspirations across disciplines and nations
}

Annelies Kusters 


\section{Deaf Studies as a transformed and transformational field: inspirations across disciplines and nations}




\section{$\nearrow$ \\ Deaf Studies as a transformed and transformational field: inspirations across disciplines and nations}




\section{$\nearrow$ \\ Deaf Studies as a transformed and transformational field: inspirations across disciplines and nations}

For whom?

Where? 


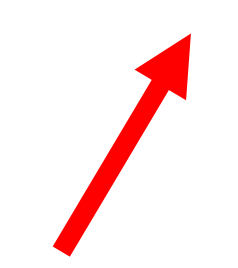

\section{Deaf Studies as a transformed and transformational field: inspirations across}

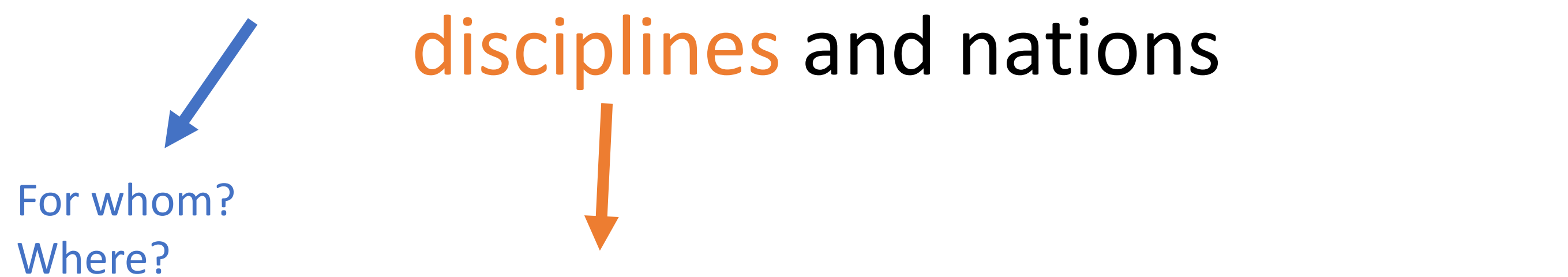

Which ones? 
Has the field matured?

Different waves?

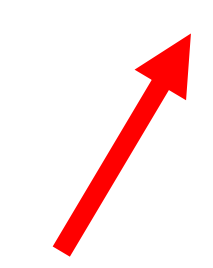

\section{Deaf Studies as a transformed and} transformational field: inspirations across

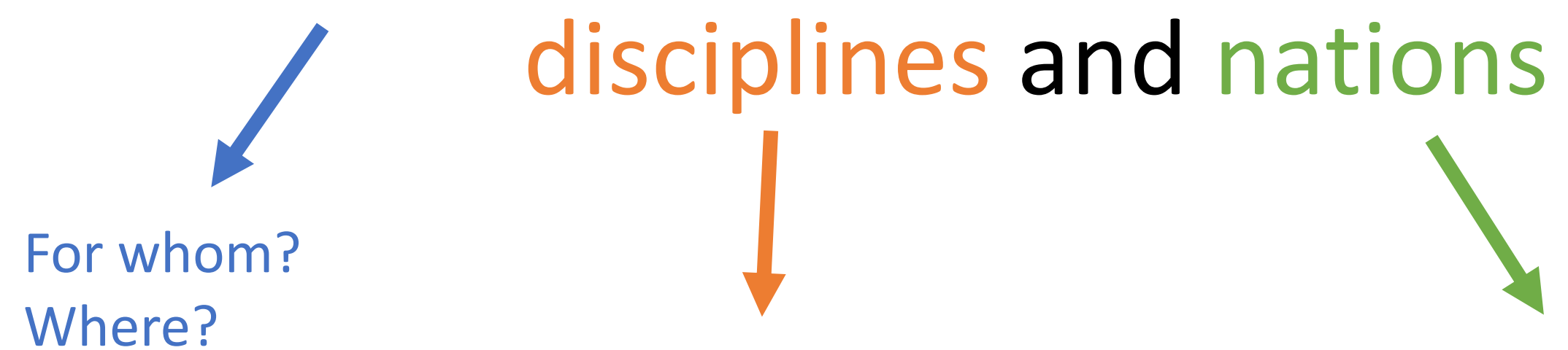




\section{Demarcating Deaf Studies}

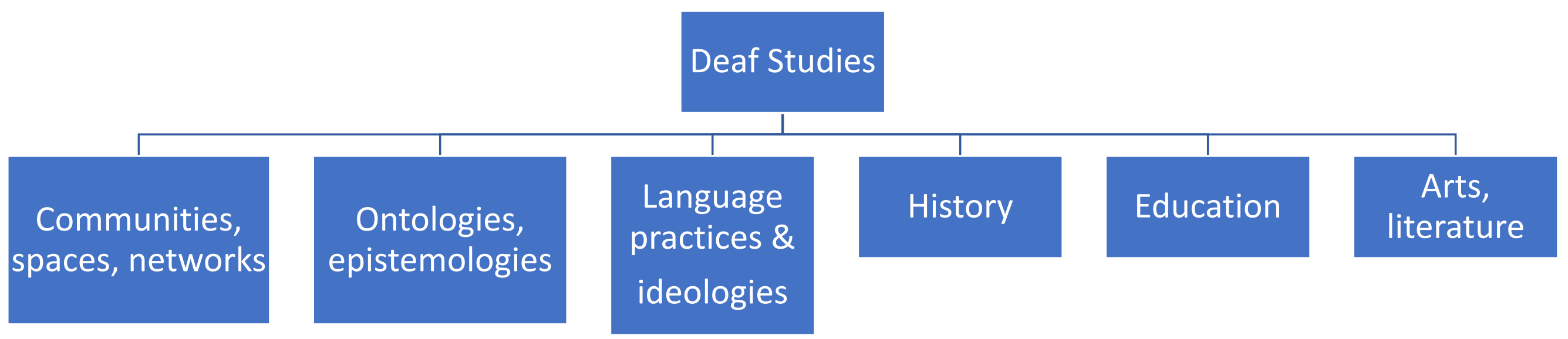




\section{Demarcating Deaf Studies}

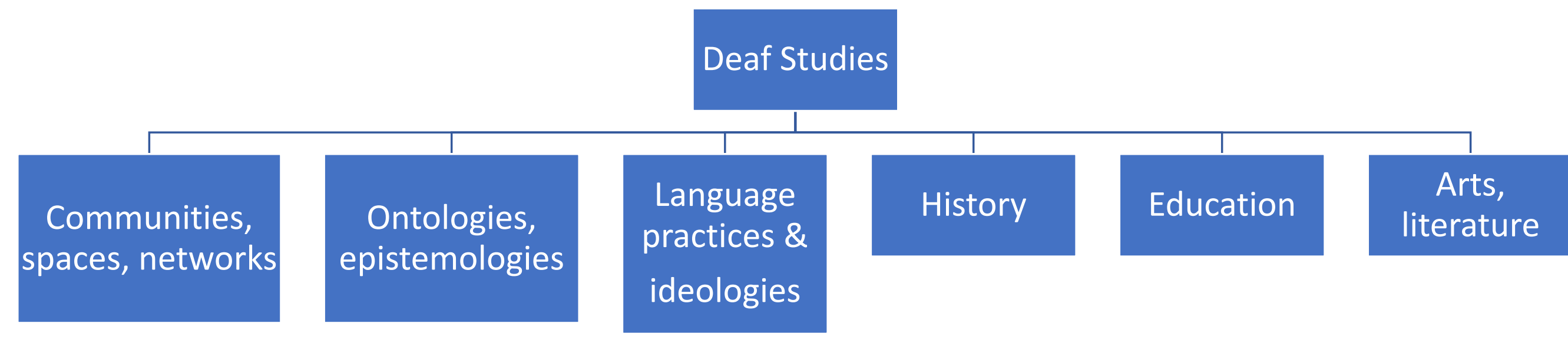

Sign language teaching/ learning?

Neuroscience?

Sign language

interpreting?

Sign

linguistics? 


\section{Demarcating Deaf Studies}

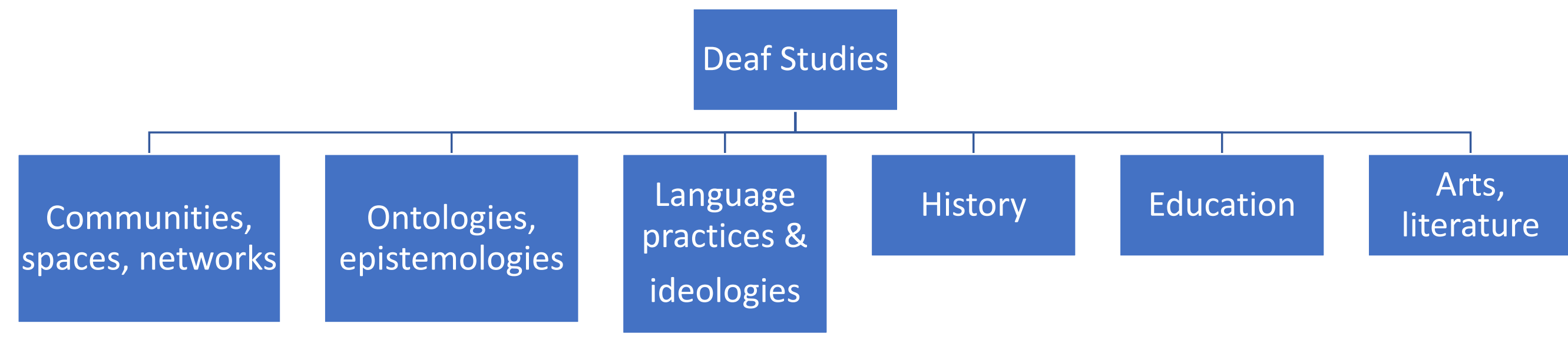

Sign language teaching/ learning?

Neuroscience?

Sign language

interpreting?

Sign

linguistics?

Benefit of narrow definition:

foregrounding study of deaf lives in Deaf Studies 


\section{Demarcating Deaf Studies}

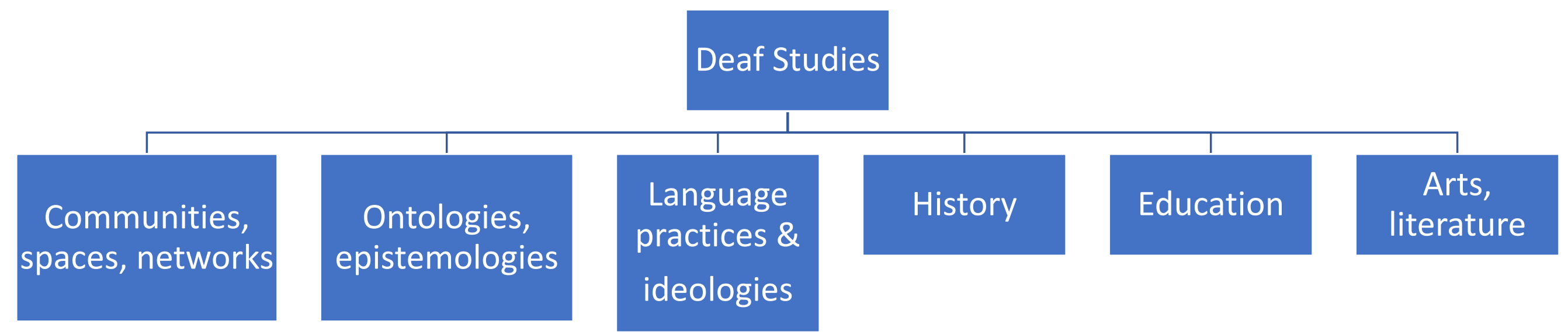

Sign language teaching/ learning?

Neuroscience?

Sign language

interpreting?

Sign

linguistics?

Benefit of narrow definition: foregrounding study of deaf lives in Deaf Studies
Benefit of including these:

- connecting strands

- unified ethical guidelines? 


\section{Demarcating Deaf Studies}

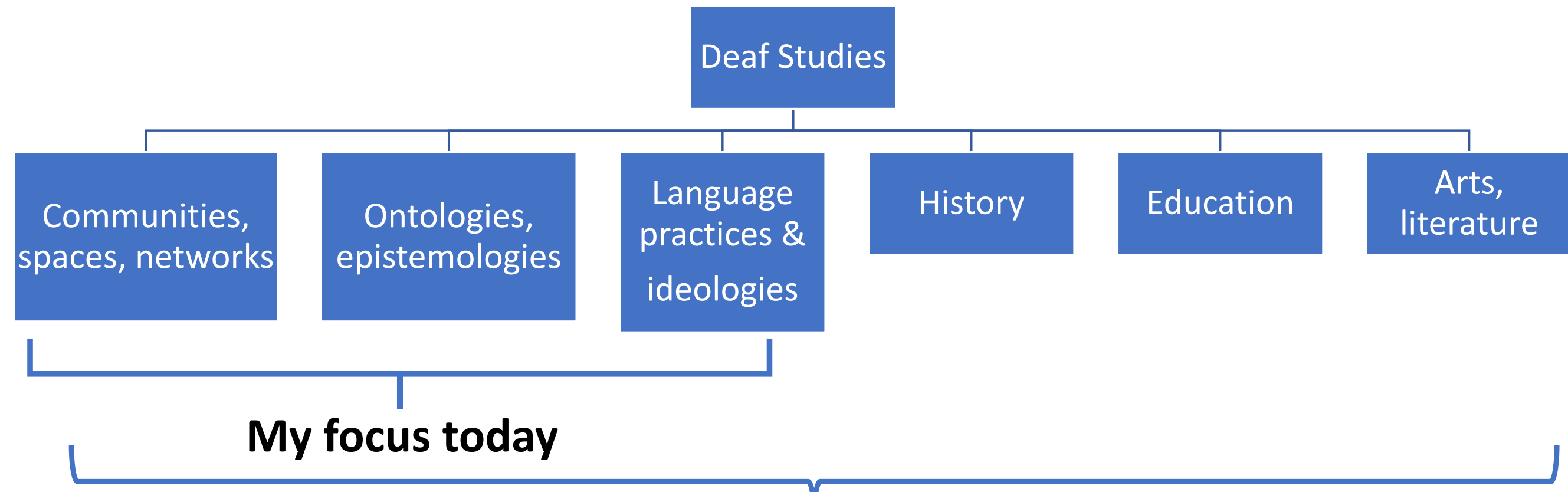
Sign language
teaching/
learning?

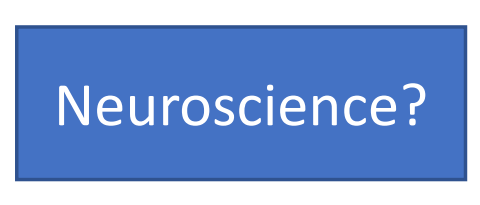

Sign language

interpreting?

\section{Sign}

linguistics?

Benefit of narrow definition: foregrounding study of deaf lives in Deaf Studies

Benefit of including these:

- connecting strands

- unified ethical guidelines? 


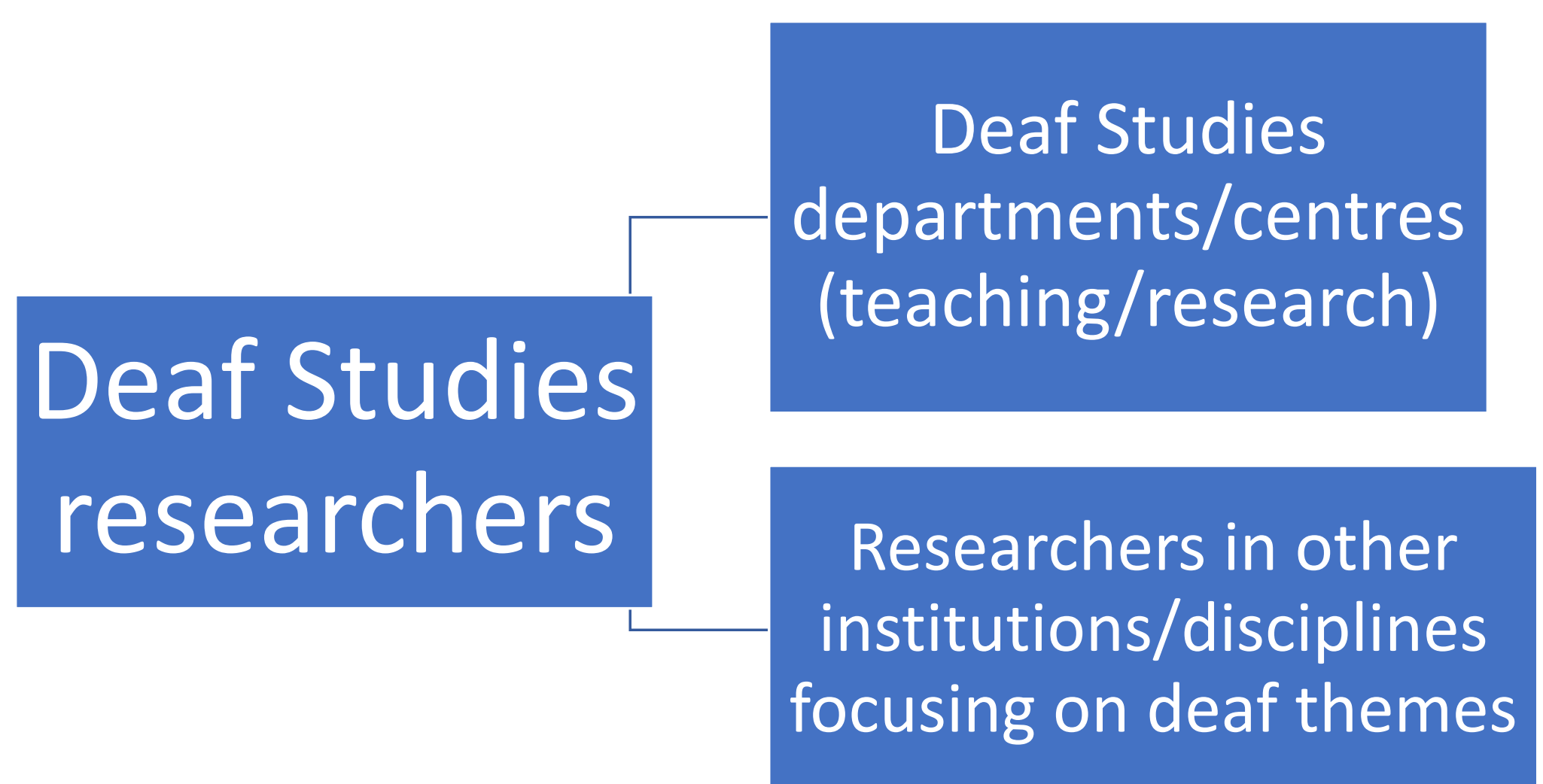




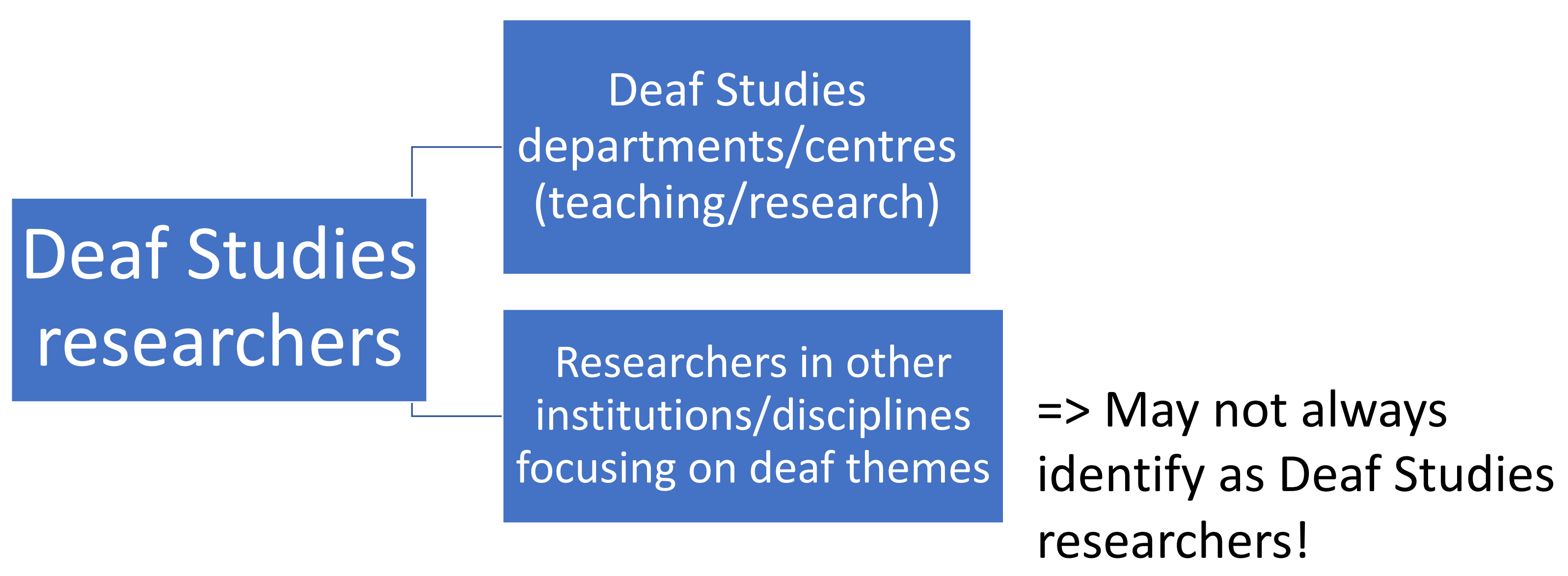




\section{The Foundation of Deaf Studies}

- Field has existed since late 1970s, mainly UK and USA

- Foci during early Deaf Studies:

1. Overturning medical/deficit model of deafness

2. Description and validation of deaf communities and cultures (Deaf clubs and schools as central places; checklists of cultural traits)

3. Addressing and challenging oppression (oralism, audism, liberation, empowerment) 


\section{What is Current in Deaf Studies?}

- Underrepresented and underprivileged groups (race, gender, sexual orientation, class, ...)

- Language ideologies and everyday language use, multimodality

- Deaf spaces/networks

- Rights and development: citizenship, human rights, group rights, language rights, sustainable development

- Study of deaf sameness/differences in international contexts 


\title{
Deaf ontologies = deaf ways of being
}

\author{
What kind of research do \\ deaf scholars produce, \\ informed by their experience \\ of being deaf?
}

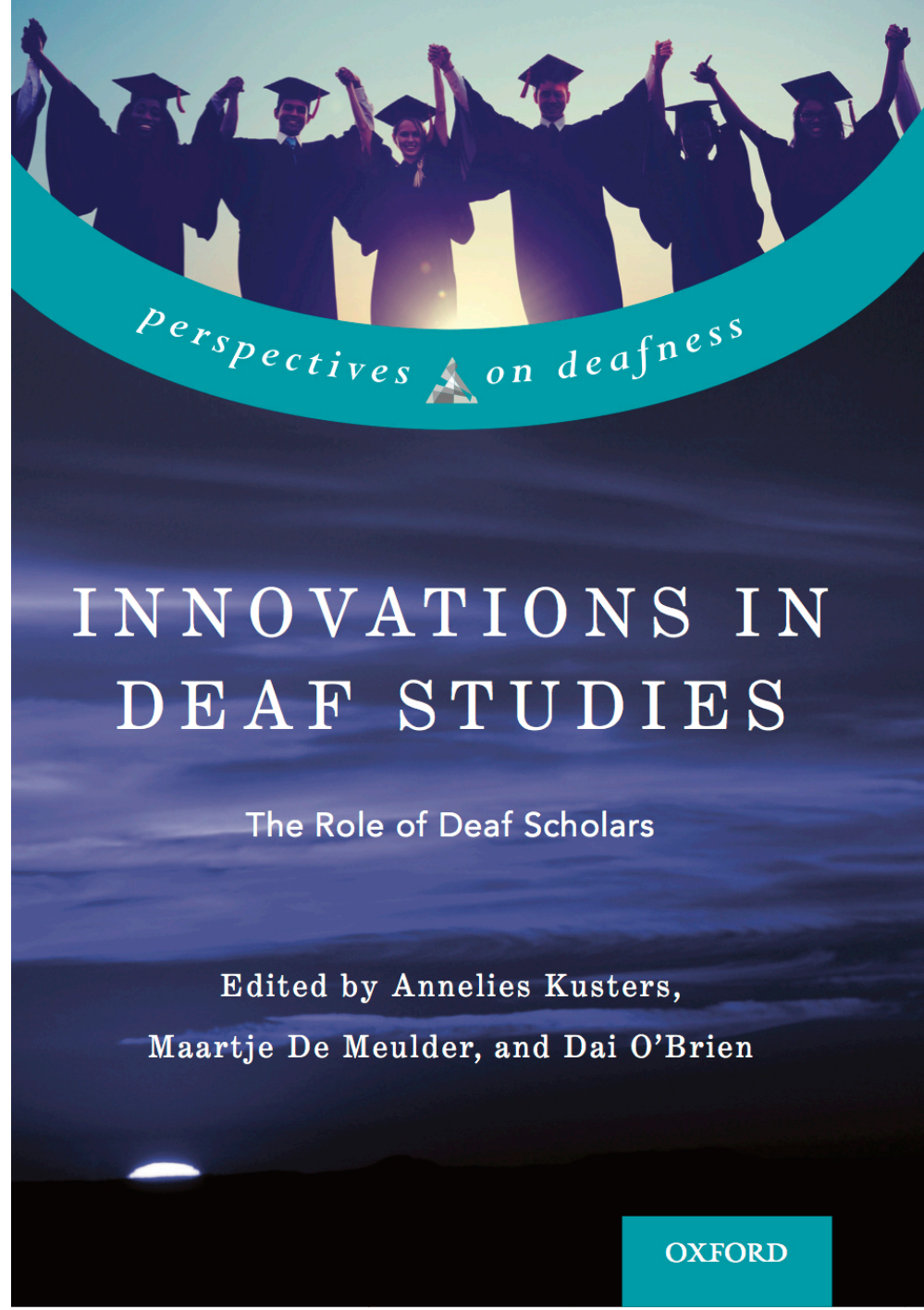




\section{Deaf Studies: White and Western?}

- Deaf Studies: white/Western discipline?

- White people disregarding non-white experiences

- White people doing research in non-white contexts/countries

- Impacts:

- Methodologies

- Theoretical frameworks (eg. "deaf culture")

- Unequal power relationships (within research and in general)

- Evolutionist/teleological perspectives (eg. deaf identity = "being developed", one way) 


\section{Deaf Studies as a transformed and transformational field: inspirations across disciplines and nations \\ - How/who can Deaf Studies inspire? \\ - Where do we get inspiration for Deaf Studies research?}




\section{Example: Research Guided by Foundational Framework of Deaf Studies}

- Background: list with thesis topics for MA in Anthropology: topic "deaf culture"

- Context (2004)

- First steps in "deaf world"

- First steps in Deaf Studies research

- Reading: Deaf Studies classics

- Theme: "Deaf culture in Surinam"

- Picked Surinam because of Dutch heritage

- One deaf school in the country (in Paramaribo), residential
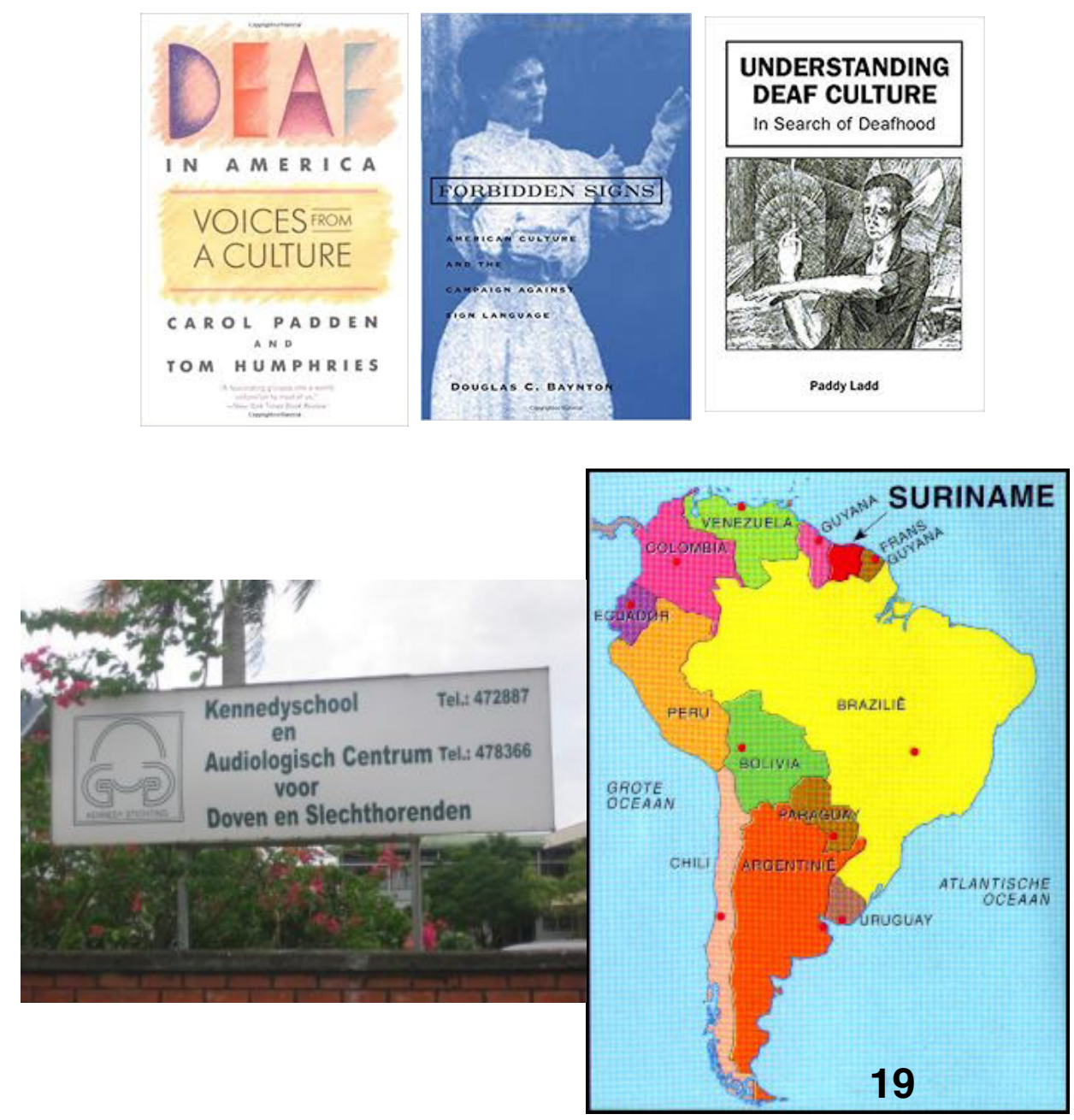


\section{Methodology:}

- Participant observation in school, boarding school, club for adults, social events

- 370 pages of field notes in 2,5 months

- Interviews with deaf children, deaf adults, educators 


\section{Methodology:}

- Participant observation in school, boarding school, club for adults, social events

- 370 pages of field notes in 2,5 months

- Interviews with deaf children, deaf adults, educators

Interview questions examples (checklist style):

- Would you prefer marrying a deaf or a hearing person?

- Do you think deaf people are disabled?

- What are differences between deaf and hearing people?

- Do you have jokes about hearing people? About deafness?

- Is there a lot of gossip?

- Do you know the concept "deaf culture?" What does it mean? 


\section{Methodology:}

- Participant observation in school, boarding school, club for adults, social events

- 370 pages of field notes in 2,5 months

- Interviews with deaf children, deaf adults, educators

Interview questions examples (checklist style):

- Would you prefer marrying a deaf or a hearing person?

- Do you think deaf people are disabled?

- What are differences between deaf and hearing people?

- Do you have jokes about hearing people? About deafness?

- Is there a lot of gossip?

- Do you know the concept "deaf culture?" What does it mean?
Brief answers, not understanding (especially children)
Not the best approach to gather data in this context 
- Themes and places that emerged as important (from conversations/listening/participating rather than interviewing!)

- Key deaf places in Paramaribo

- "Holland": Colonial heritage; import of signs; migration; holidays

- Emancipation/Empowerment/Participation (teaching sign language, driver's licenses, employment, leadership in alumni association)

- Struggle with "deaf culture" concept

- checklists

- In Surinam: unfamiliarity with concept

- "Deaf culture" as processual concept 


\section{Deaf Culture Concept: Challenges}

- Overused?

- Too broad?

- Static?

- Deaf vs hearing culture?

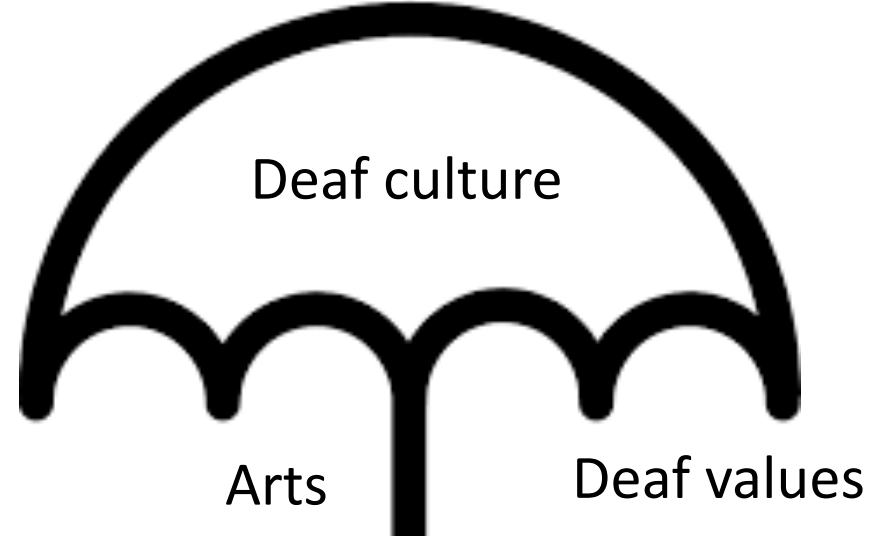

- Deaf cultures? 


\section{Deaf Culture Concept: Challenges}

- Overused?

- Too broad?

- Static?

- Deaf vs hearing culture?

- Deaf cultures?

- Experimenting

- Narrowing? (arts/theatre?)

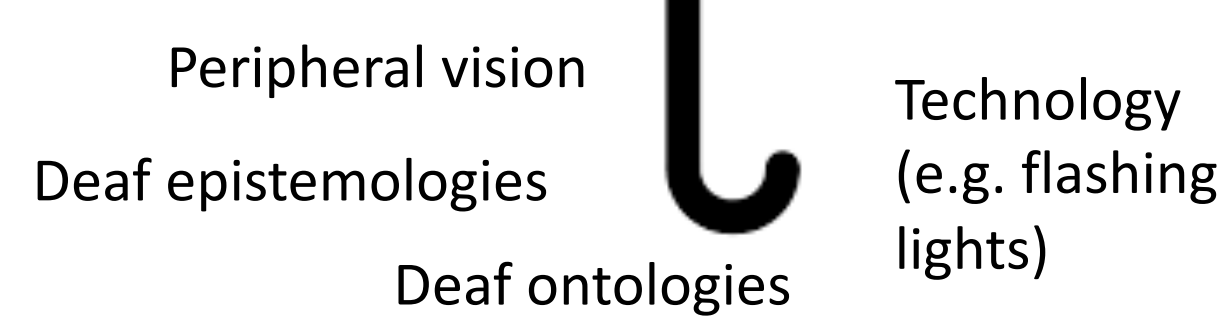

Concepts framing academic analysis

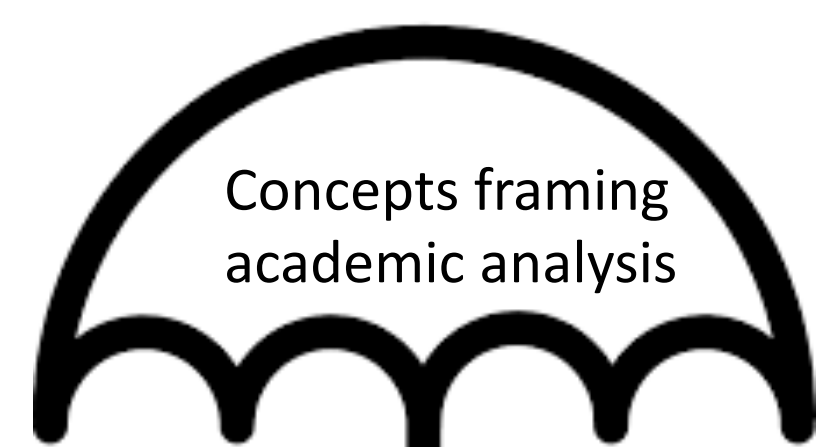

Deaf culture

Deaf epistemologies

Deaf sociality Deafhood
Deaf ontologies

Deaf spaces

Deaf Gain intersectionality 


\section{Example: Mumbai trains}

- Trip to India in Nov 2006 (camp/tourism): observed deaf navigating Mumbai => MSc Deaf Studies dissertation

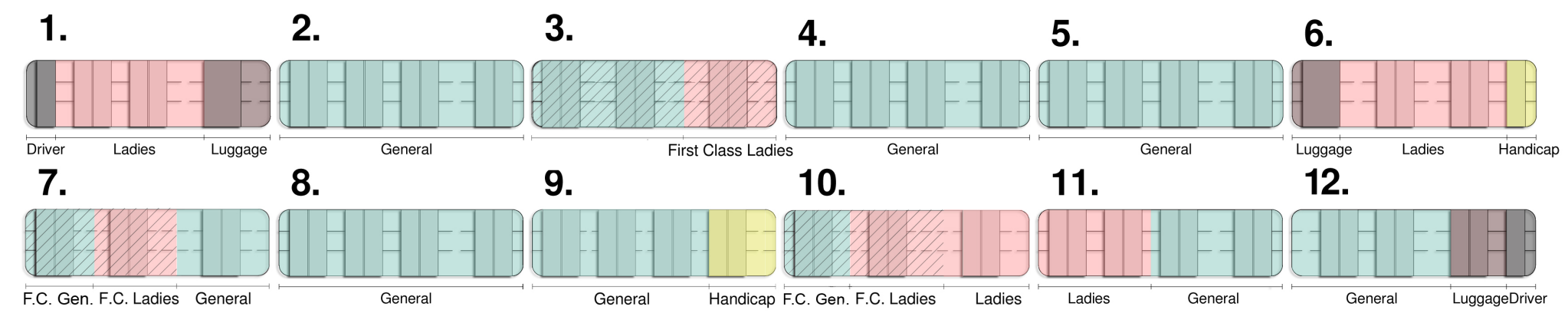

- Deaf people socializing in so-called "handicapped compartments" in Mumbai trains => Dissertation topic narrowed down

- Inspired by "deaf geographies"

- Value of longitudinal perspective: follow up research in 2013-2014

- focus on relationship deaf \& disabled

- focus on intersection of deaf \& (trans)gender 


\section{Example: Shared Signing Communities}

- Past: Martha's Vineyard

- Well-known present examples:

- Chican, Mexico

- Bengkala (Desa Kolok), Bali

- Al-Sayyid Bedouin, Israel

- Adamorobe, Ghana

- Some researchers stated that: "no deaf culture", "no deaf community", "no deaf-only activities"

- Deaf experiences $=$ ?

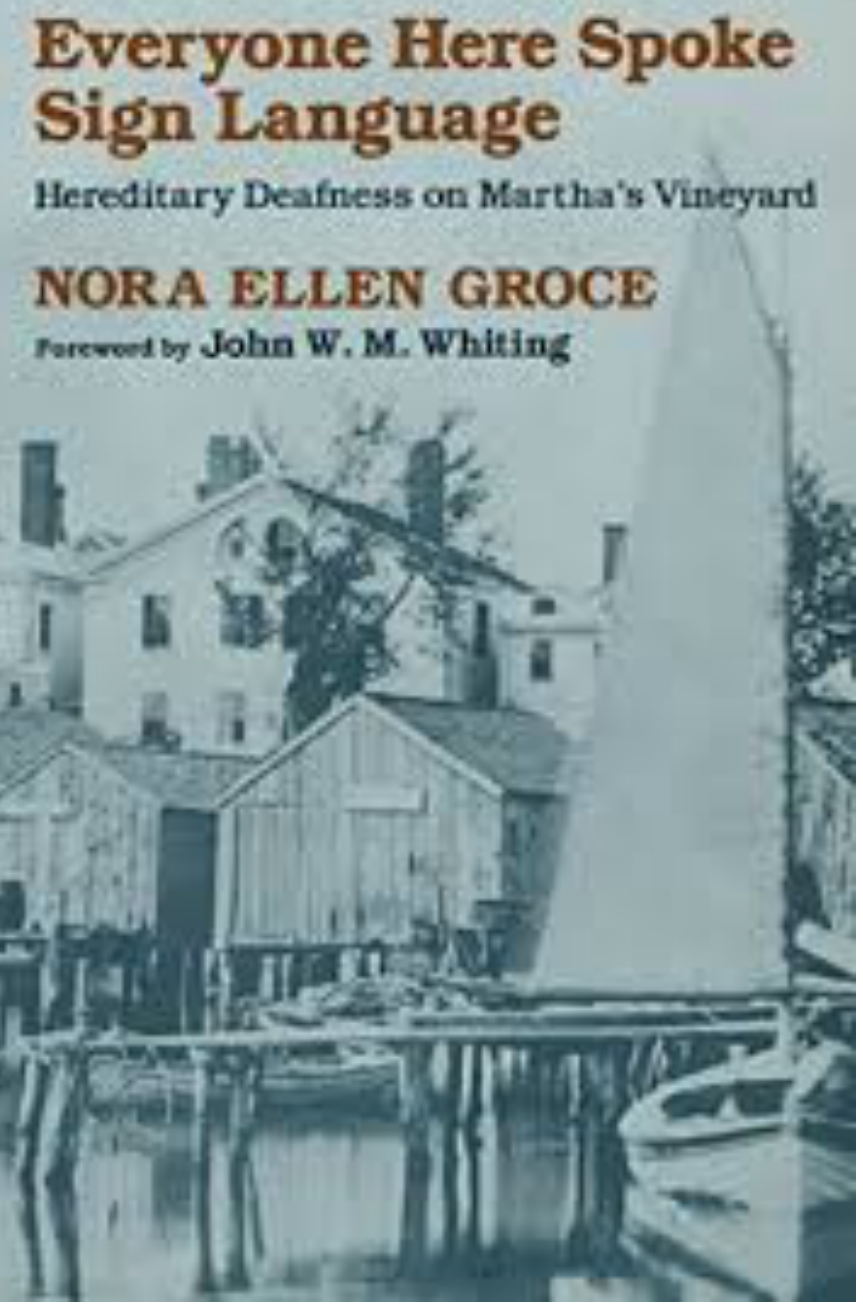


Adamorobe, Ghana $\mathrm{PhD}$ research 2008-2009

Deaf culture?

Deaf people: part of wider village and hearing family whilst also setting up deaf spaces to engage in deaf sociality
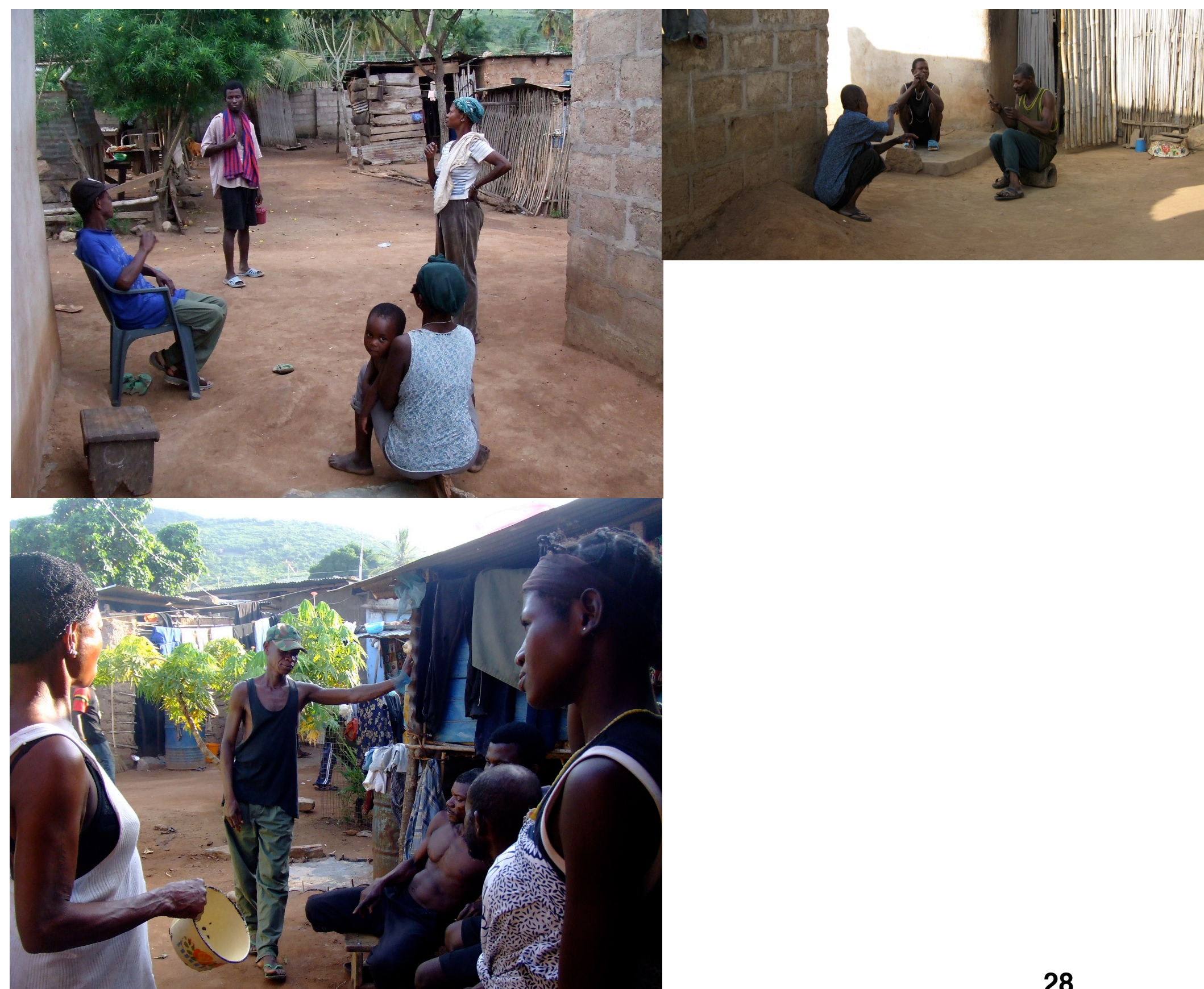
Adamorobe, Ghana $\mathrm{PhD}$ research 2008-2009

Deaf culture?

Deaf people: part of wider village and hearing family whilst also setting up deaf spaces to engage in deaf sociality
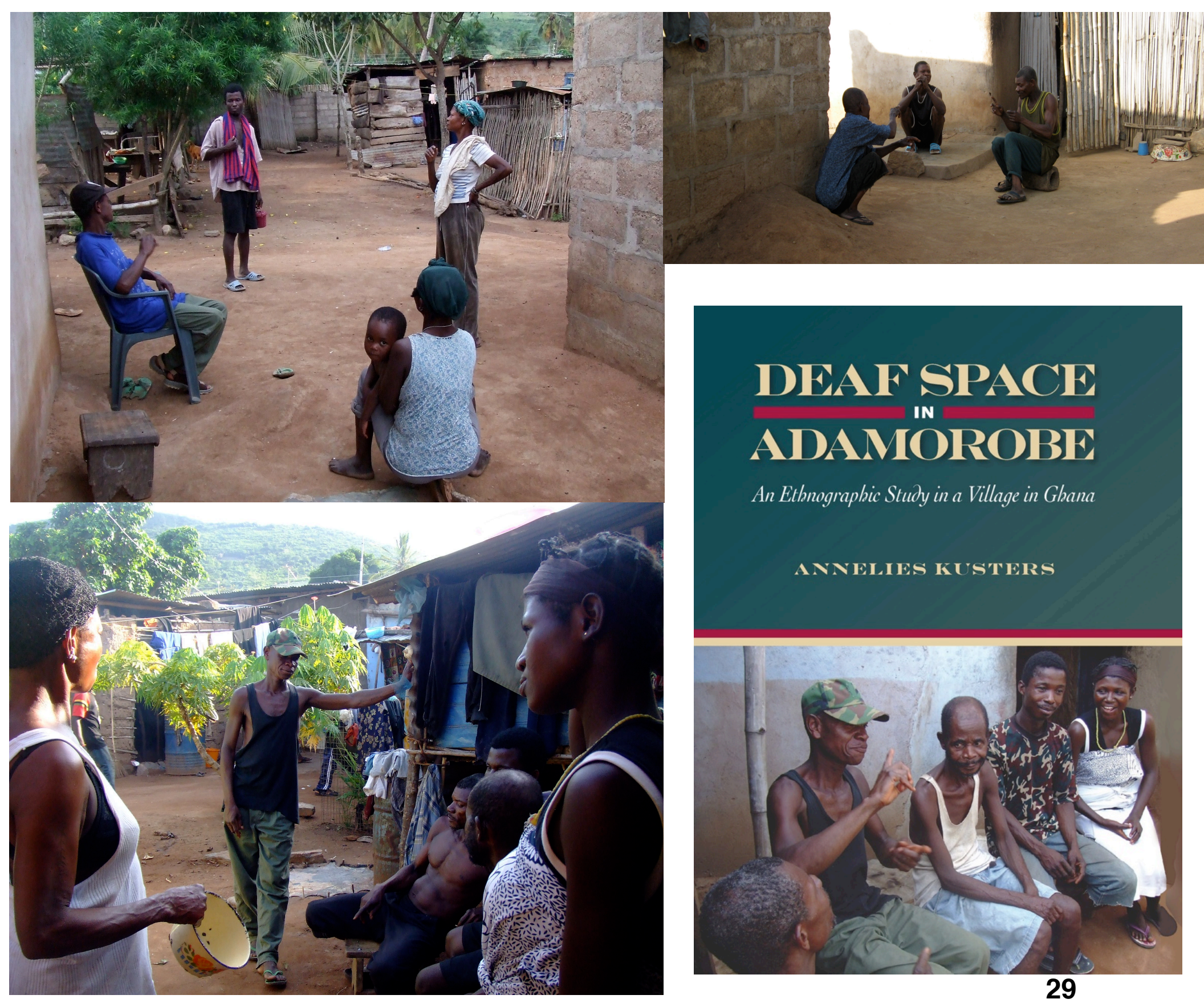
(n) 


\section{Deductive research}

Theories/ concepts

\section{Inductive research}

Collecting data
Spotting patterns
Developing theories/new concepts 


\section{Deductive research}

Theories/ concepts
Observation

Confirmation
Risk: Persistent and often uncritical use of founding concepts (e.g. Deaf culture)

\section{Inductive research}

Collecting data
Spotting patterns
Developing theories/new concepts 


\section{Deductive research}

Theories/ concepts
Observation

Confirmation
Risk: Persistent and often uncritical use of founding concepts (eg. Deaf culture)

\section{Inductive research}

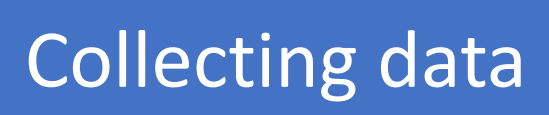

Spotting patterns

\section{Developing} theories/ concepts
Risk: no theory may emerge + time-consuming

But we don't have enough of this in Deaf Studies! 


\section{Distinction between academic and everyday use:}

Even if we experiment with new concepts in academia, "deaf culture", "deaf community", "deaf world" etc. are widely used in everyday discourses in some deaf communities!

Important to acknowledge that + study how the concepts are used! (deaf epistemologies) 


\section{Also: Engage with Current Mainstream}

\section{Theories/Concepts}

- Examples:

- Translanguaging

- Linguistic repertoires

- Superdiversity

- Intersectionality

- Mobilities

- Geography of disability

- Translocality
- And inspire other disciplines!

- How?

- Publishing

- Networking (small events attended by experts are ideal for networking!)

- Get funding for events and invite experts

- Period(s) of study/work in nondeaf universities/research centres

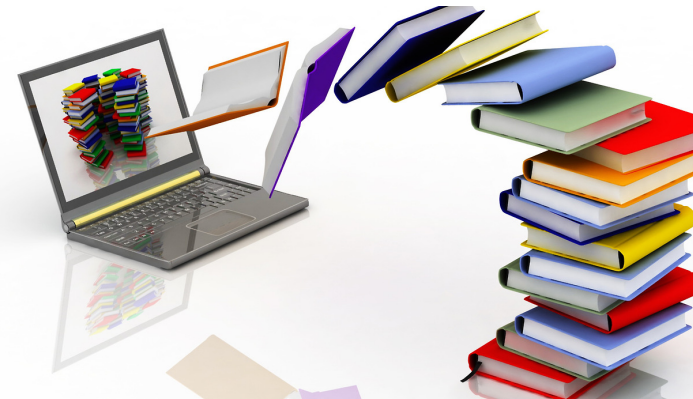

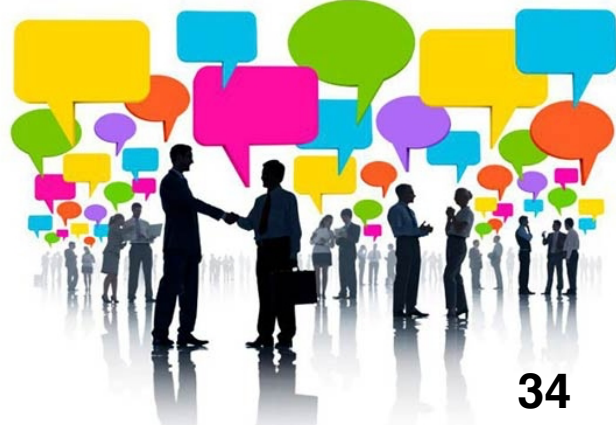




\section{Example: Research in Mumbai}

- Postdoc in Germany, institution focusing on study of diversity, eager to fund a film

- Focus on customer interactions: shops, restaurants, transport. Six deaf people (one deaf blind) who sell and buy, order or serve, and travel.

- Meta-linguistic reflection on gesturebased translanguaging: study of language ideologies

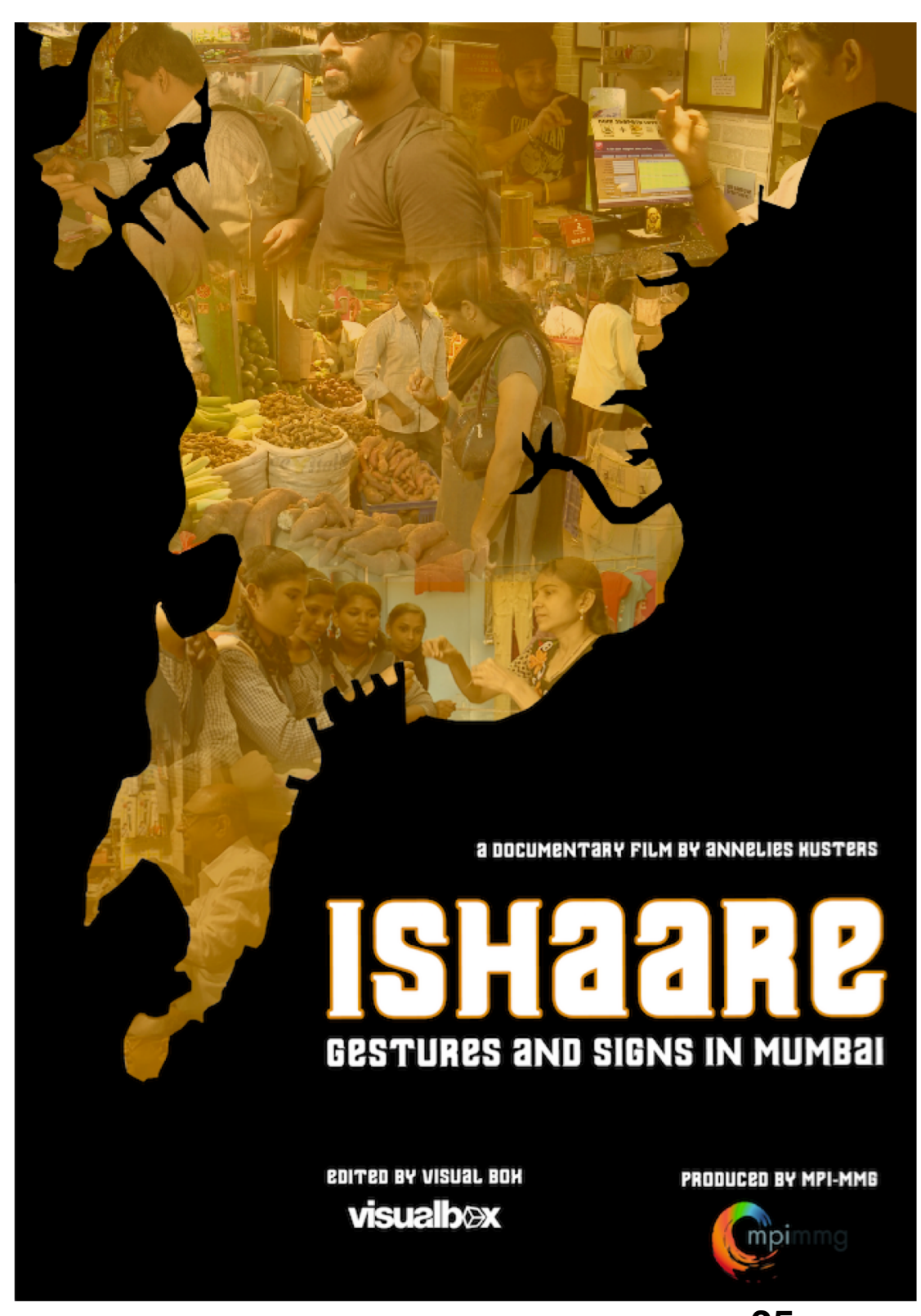

- Creation of ethnographic film: Ishaare: Gestures and Signs in Mumbai (online!) 

Studies of multimodality
Studies of multilingualism/ translanguaging 

Studies of multimodality

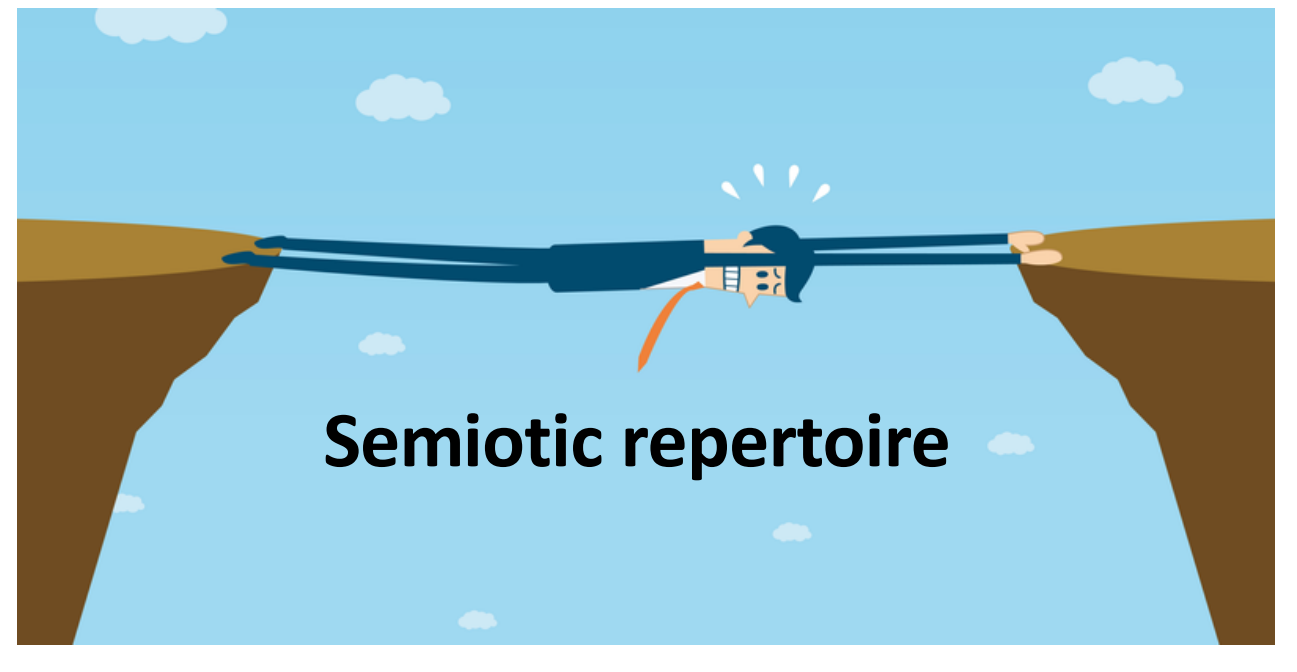

\section{Studies of} multilingualism/ translanguaging 


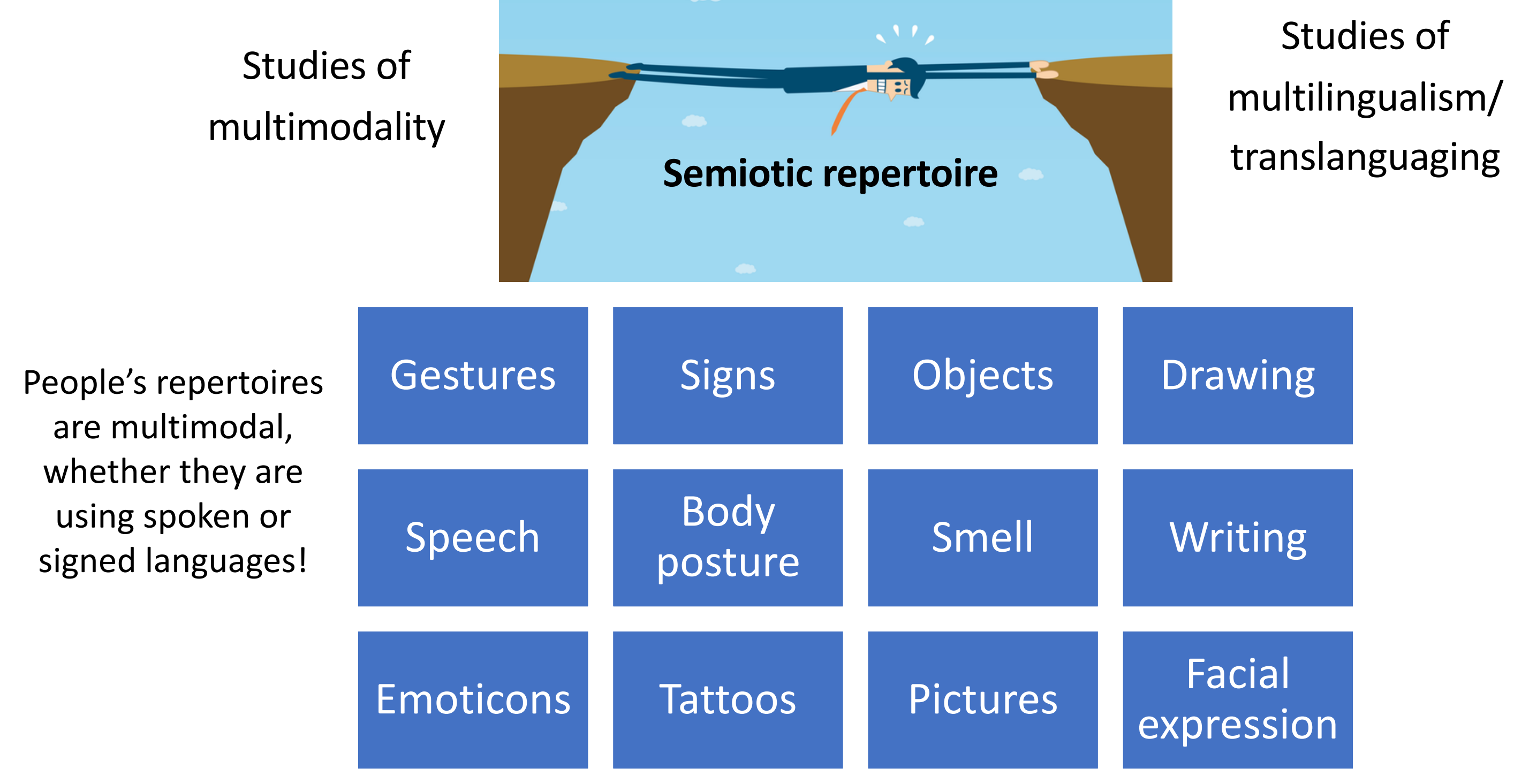




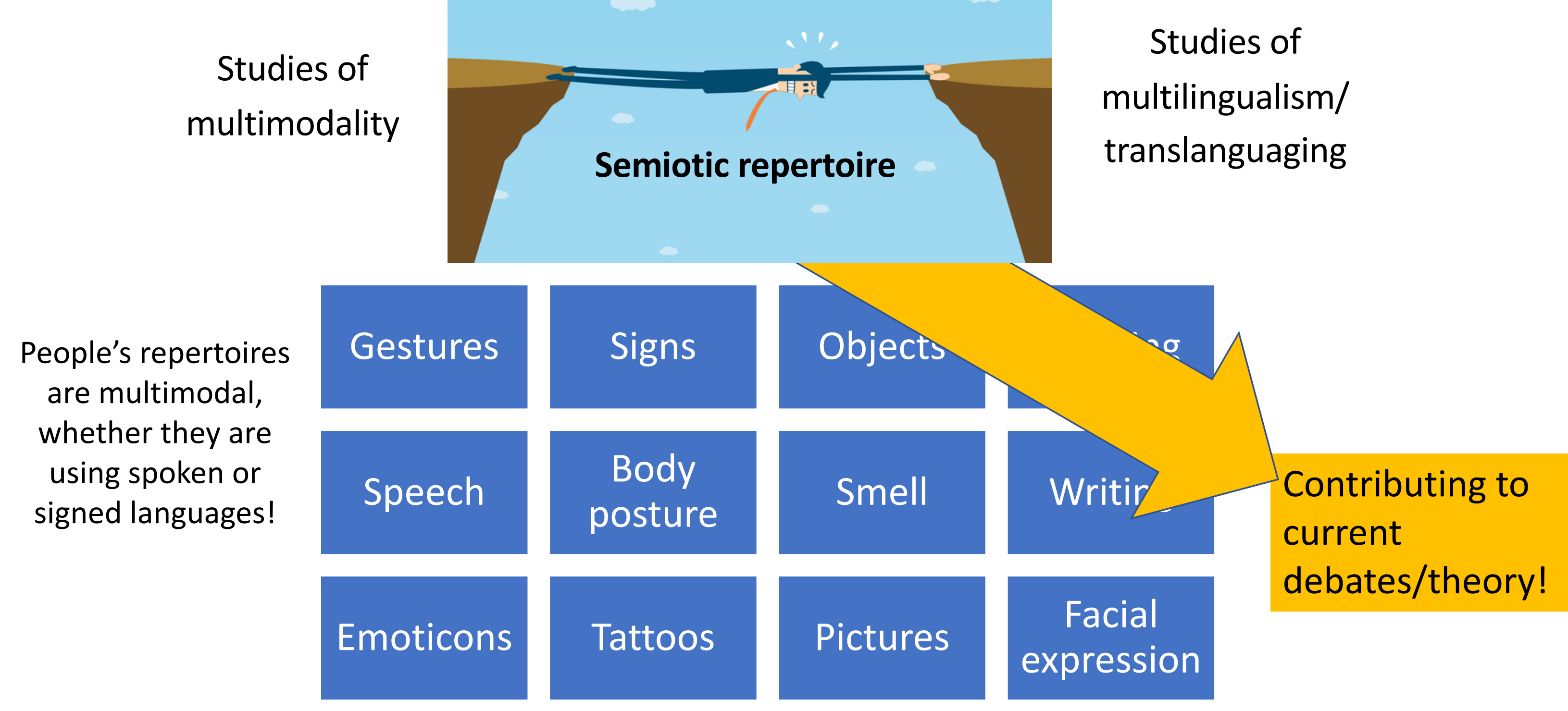

(Kusters, Spotti, Swanwick, Tapio 2017) 


\section{mobile deaf}

HERIOT

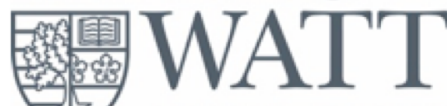

Deaf mobilities across international borders: Visualising intersectionality and translanguaging

ERC Starting Grant - 2017-2022

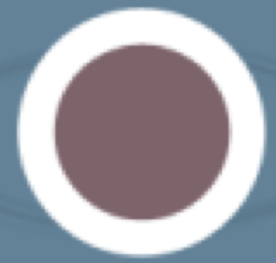

Lobour Migration 


\section{Intersectionality}

- Early Deaf Studies: the question "what comes first?" (eg deaf first or black first)

- The question of "what comes first" is problematic in itself! Complex realities: intersectionality

- Crenshaw (1989):

- multiple inequalities experienced by working-class black women

- gender-race-class triumvirate: being doubly/triply oppressed because of patriarchy, racism, classism

- Later: addition of other dimensions in intersectionality theory: sexuality, religion, age, disability, etc.

- But problematic if it comes to merely mean "multiple identities"! 
Cho, Crenshaw \& McCall 2013: Toward a field of

intersectionality studies: Theory, applications, and praxis "what makes an analysis intersectional-

whatever terms it deploys, whatever its iteration, whatever its field or discipline-

is its adoption of an intersectional way of thinking about the problem of sameness and difference and its relation to power.

This framing-conceiving of categories not as distinct

but as always permeated by other categories, fluid and changing, always in the process of creating and being created by dynamics of power-

emphasizes what intersectionality does rather than what intersectionality is." ( $p$ 795) 


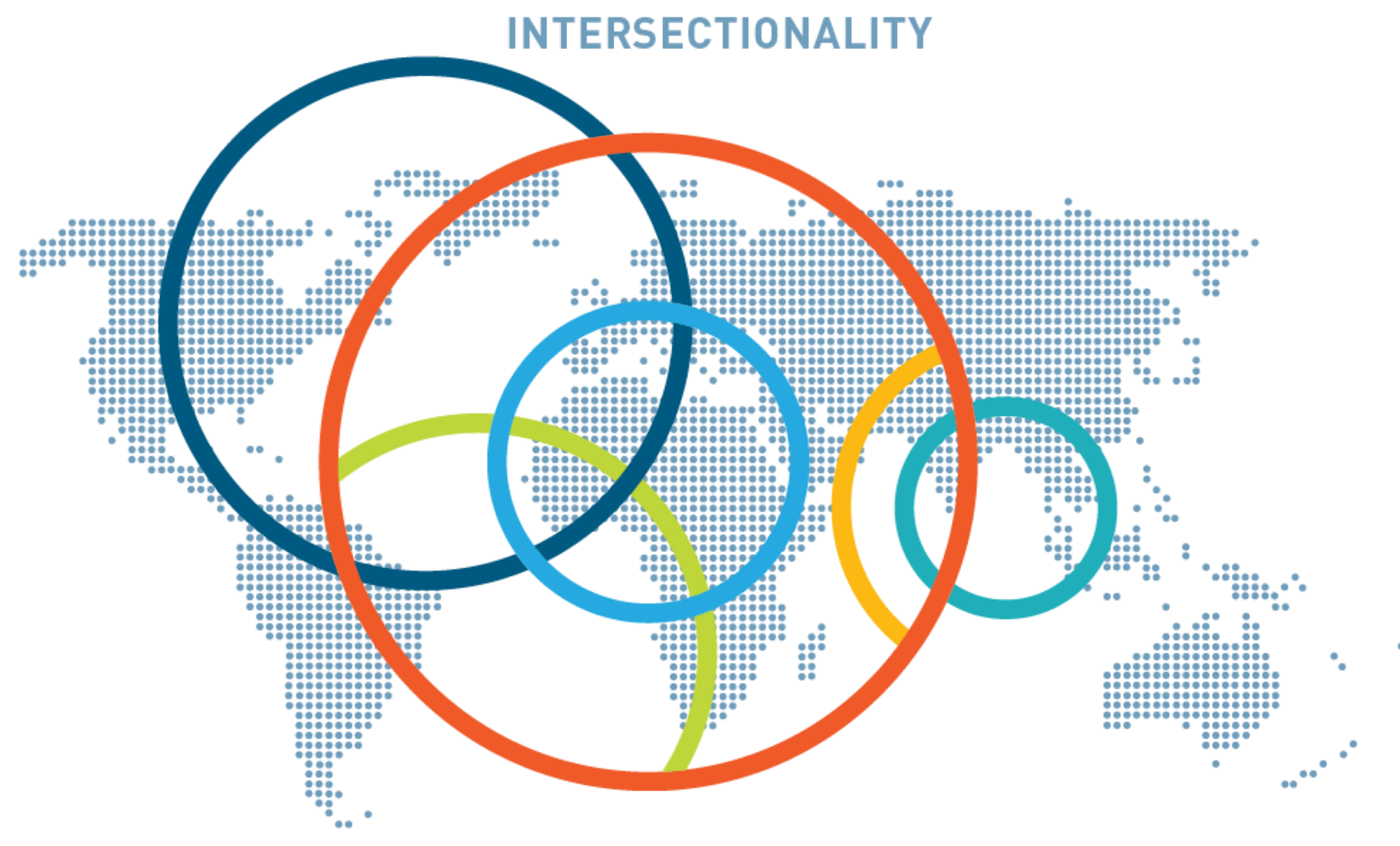




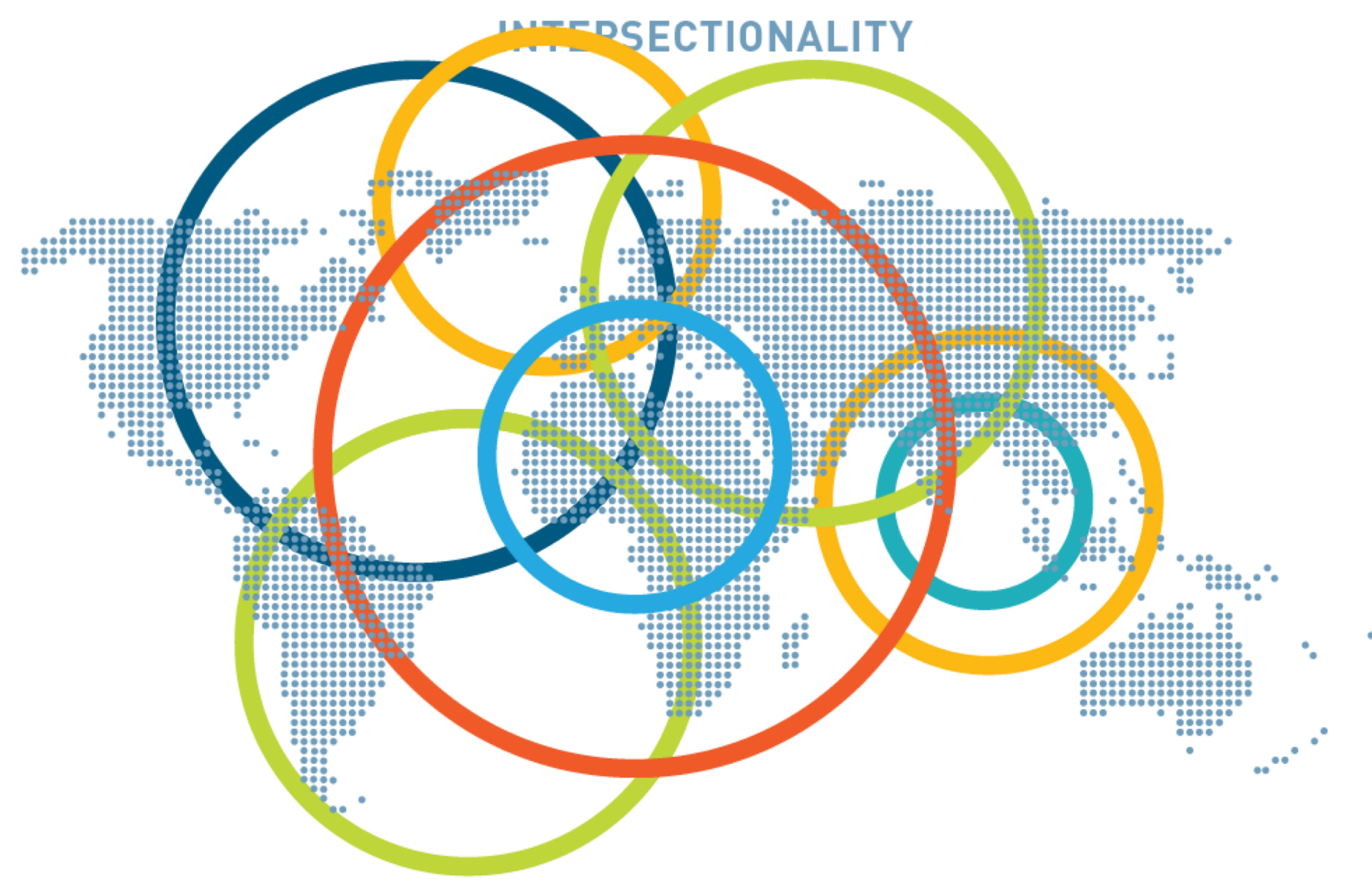




\section{TRANSLANGUAGING}

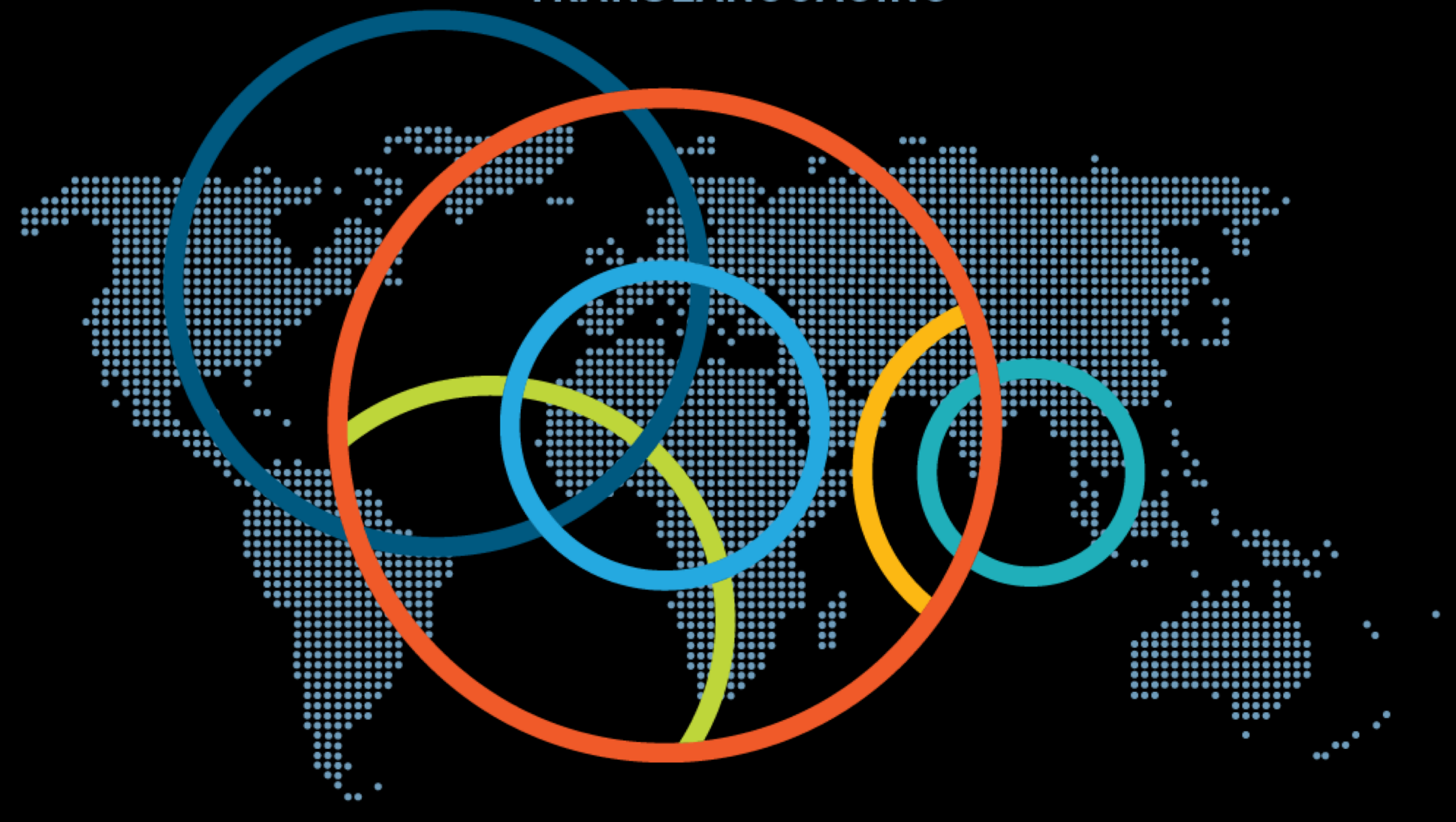




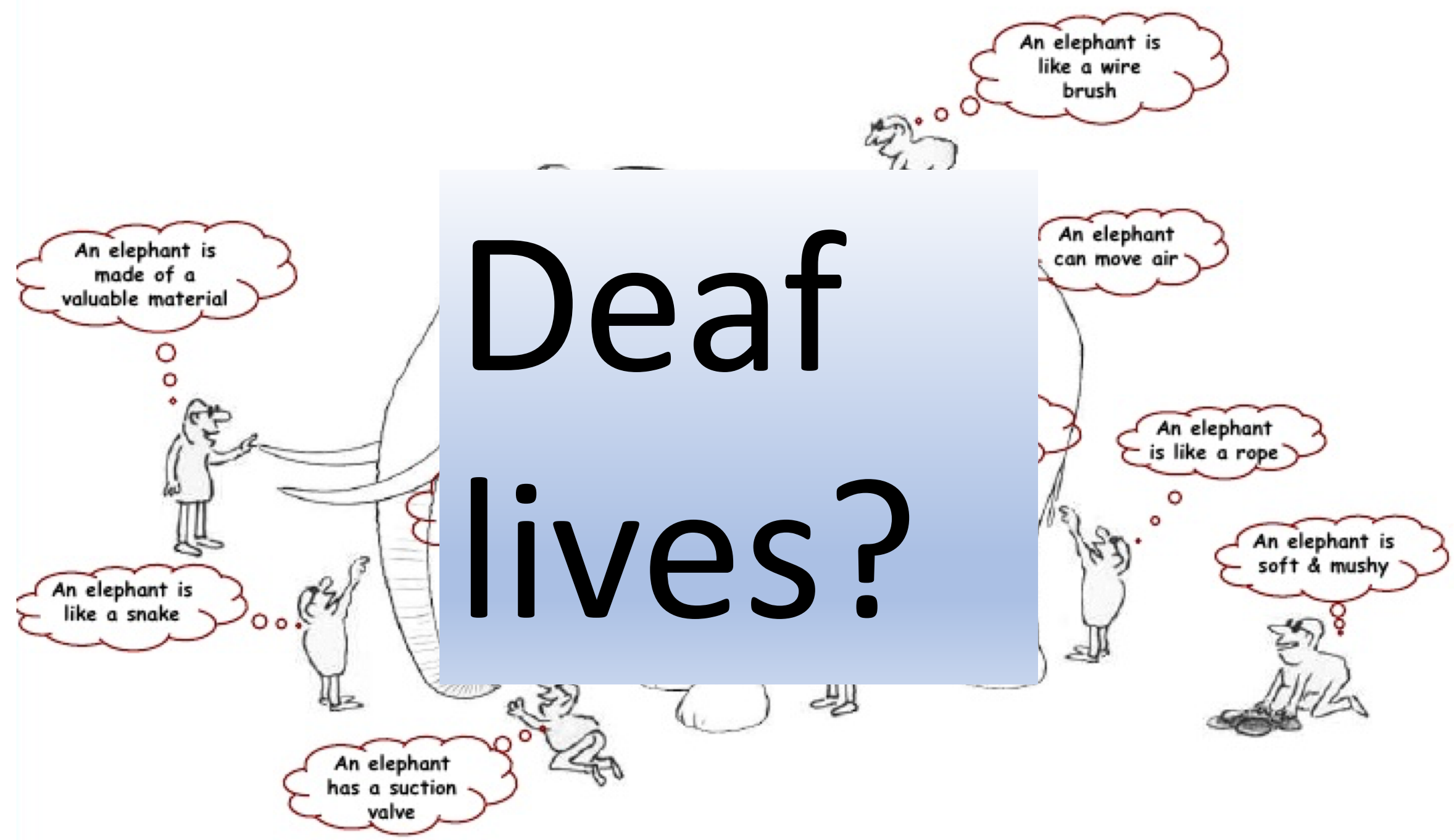



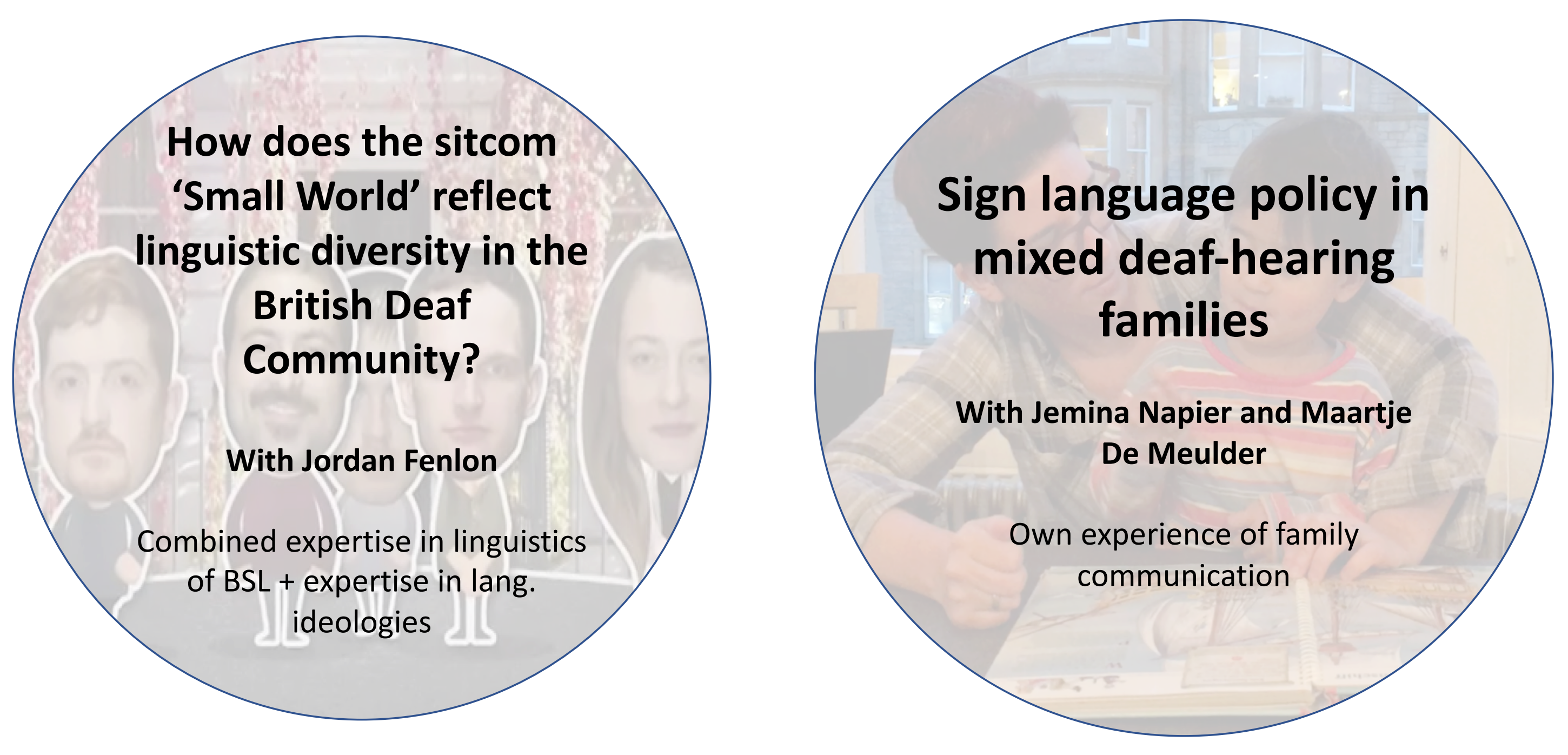


\section{Collaboration}

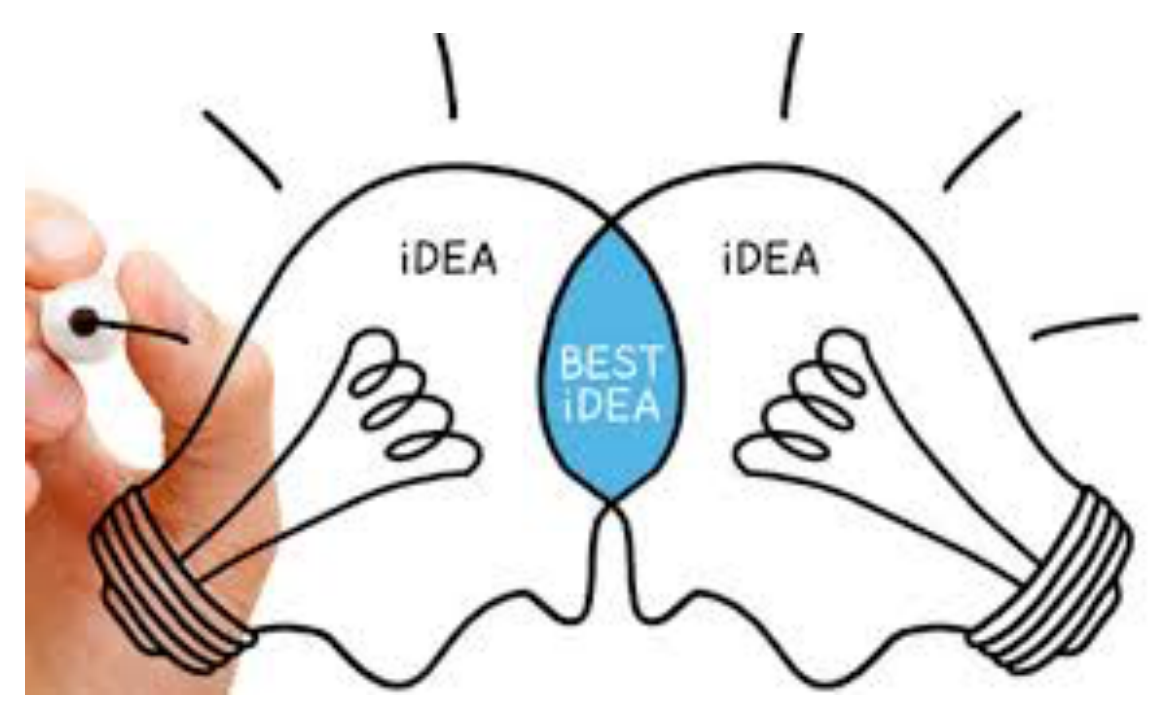

- Cross-fertilization and collaborative projects

- Be open to collaboration with people focusing on other disciplines even if you initially feel dislike (e.g. theoretical sign linguistics and disability studies are often avoided by Deaf Studies scholars) 


\section{Deaf Studies as a Field, Today}

\section{Transdisciplinary}

\section{Interdisciplinary}

Multidisciplinary

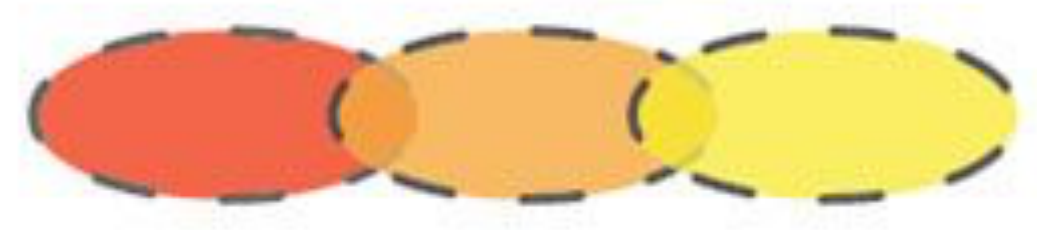

Disciplinary
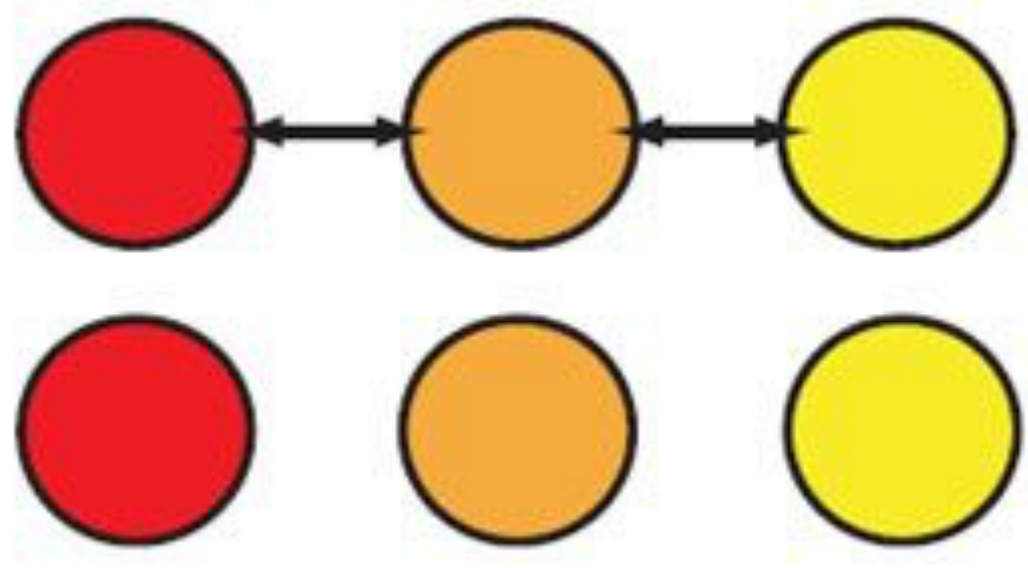

- Deaf Studies: traditionally multidisciplinary

- But has been turning around in circles (referring mostly to other Deaf Studies work!)

- Only recently more interdisciplinary: infiltrating mainstream academy (journals!), co-organized events, keynotes

- Should we strive more for transdisciplinarity? (dissolving boundaries between conventional disciplines) 


\section{Does it (Still) Make Sense to Talk About Deaf Studies as a Field?}

- NO,

- Not an isolated monolithic body (anymore)

- Outside of US: not always beneficial to brand oneself solely as a Deaf Studies scholar (very few Deaf Studies departments/centres/courses), for:

- Employment opportunities

- Research funding 


\section{Does it (Still) Make Sense to Talk About Deaf Studies as a Field?}

- NO,

- Not an isolated monolithic body (anymore)

- Outside of US: not always beneficial to brand oneself solely as a Deaf Studies scholar (very few Deaf Studies departments/centres/courses), for:

- Employment opportunities

- Research funding
- YES,

- Bringing together different approaches to research on deaf lives

- There are (still) theories/concepts/discussions that are specific to Deaf Studies

- E.g. methodology, ethics, deaf ontologies

- Importance of courses, edited volumes, journal issues, conferences (e.g. summer schools, Global Deaf Studies conference in Berlin, 2021, organized by HU Berlin and MobileDeaf) 


\section{Deaf Studies as a transformed and transformational field: inspirations across disciplines and nations}


New concepts/theories Inductive

More deaf researchers

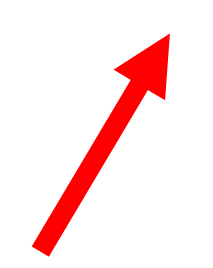

Deaf Studies as a transformed and transformational field: inspirations across disciplines and nations 
New concepts/theories Inductive

More deaf researchers

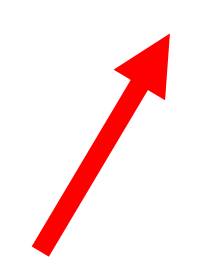

\section{Deaf Studies as a transformed and} transformational field: inspirations across disciplines and nations

Deaf lives

Other lives/fields

Visual methods/filmmaking:

data, dissemination 
New concepts/theories Inductive

More deaf researchers

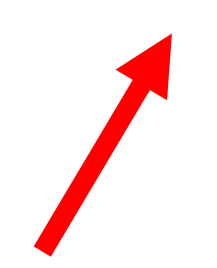

\section{Deaf Studies as a transformed and transformational field: inspirations across disciplines and nations}

Deaf lives

Other lives/fields

Visual methods/filmmaking:

data, dissemination

Not just multidisciplinary

or interdisciplinary

but transdisciplinary 
New concepts/theories Inductive

More deaf researchers

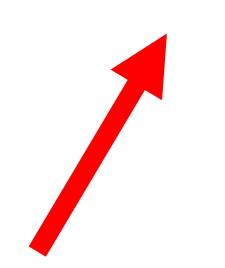

\section{Deaf Studies as a transformed and transformational field: inspirations across}

Deaf lives

Other lives/fields

Visual methods/filmmaking:

data, dissemination disciplines and nations 

transformational field: inspirations across

Deaf lives

Other lives/fields

Visual methods/filmmaking:

data, dissemination

disciplines and nations

Not just multidisciplinary

or interdisciplinary but transdisciplinary?
International Transnational

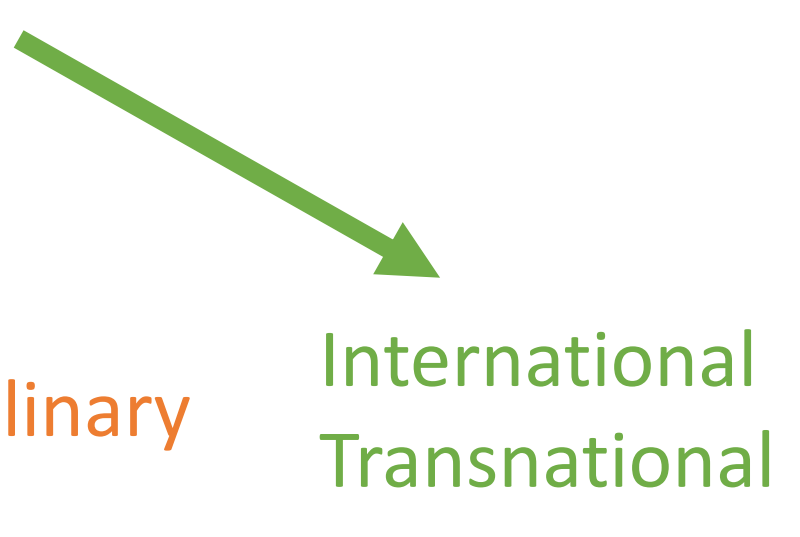



transformational field: inspirations across

Deaf lives

Other lives/fields

Visual methods/filmmaking:

data, dissemination

disciplines and nations

Not just multidisciplinary

or interdisciplinary

but transdisciplinary? ?
International Transnational

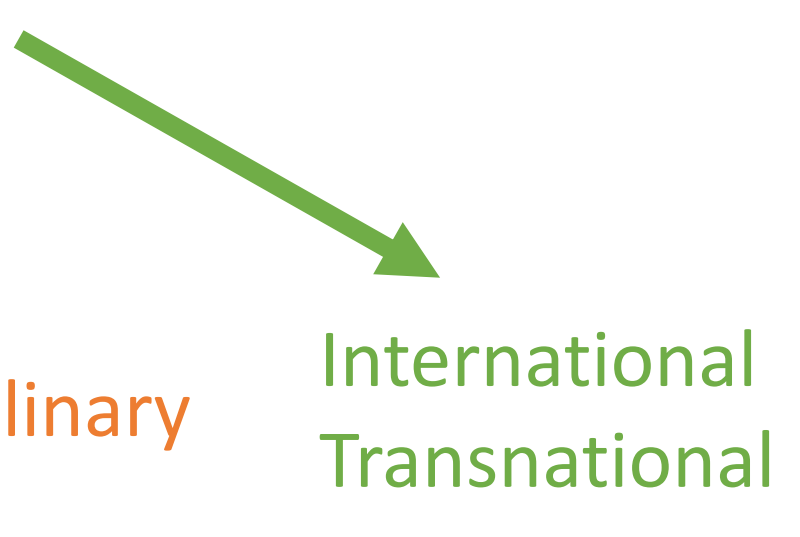

